\title{
ROLE OF INTRAVENOUS UROGRAPHY AND TRANSABDOMINAL ULTRASONOGRAPHY IN THE DIAGNOSIS OF BLADDER CARCINOMA
}

\author{
MUHAMMAD RAFIQUE, ABRAR A. JAVED \\ Instar Medical College, Multan, Pakistan
}

\begin{abstract}
Introduction: The present study was carried out to compare the efficacy of transabdominal ultrasonography and intravenous urography in the diagnosis of bladder carcinoma in those patients presenting painless hematuria.

Materials and Methods: Medical records of 100 patients who had both ultrasonography and intravenous urography were studied. The reported findings of these investigations were correlated with those of cystoscopy.

Results: Ultrasonography was significantly more sensitive (96\%) in the detection of bladder carcinoma compared to urography (87\%). By applying the test of equality of proportions, the value of $\mathrm{Z}$ is 2.28 , which is statistically significant $(\mathrm{p}<0.01)$. In addition, ultrasonography was more sensitive in clarifying the pathology in upper renal tracts i.e. ureteric obstruction secondary to bladder carcinoma when urography failed due to none or poor excretion of contrast.

Comments: We recommend the use of ultrasonography as the initial radiological investigation for detection of bladder carcinomas in patients presenting hematuria. Ultrasonography is safe, easily available, cost effective and provides images of both upper and lower renal tract. Patients diagnosed to be suffering from bladder carcinoma by ultrasonography should be scheduled directly and promptly for cystoscopy and bladder tumor resection.
\end{abstract}

Key words: bladder; bladder neoplasms; ultrasonography; intravenous urography Int Braz J Urol. 2004; 30: 185-191

\section{INTRODUCTION}

Bladder cancer is a disease of significant concern. In Europe (1) and USA (2) it is the fourth most common cancer in men. In Pakistan, it is one of the top ten common cancers in men and is the most common urological malignancy. The majority of patients present painless hematuria, usually as the sole presenting symptom (3). It has been the standard urological practice to request an intravenous urogram as the initial radiological investigation of patients with hematuria. Various authors have reported on the use of transabdominal ultrasonography as the initial radiological investigation for detection of bladder carcinomas in patients presenting hematuria (4-6).
Ultrasonography is safe and easily available and provides images of both upper and lower renal tract. Confirmation of the bladder carcinoma requires cystoscopy and histopathological diagnosis of the resected tumor tissue.

The present study was carried out in the departments of Urology and Oncology of Nishtar Medical College Hospital, Multan, to compare the efficacy of urography and ultrasonography in the diagnosis of bladder carcinoma.

\section{MATERIALS AND METHODS}

In this case controlled retrospective study medical records of 122 patients who presented 
painless hematuria secondary to bladder carcinoma from January 2001 to June 2003 were evaluated. Only those patients who had both ultrasonography of urinary tract and urography were included in the study. A hundred patients satisfied this criterion. Those patients who had only one investigation i.e. urinary tract ultrasonography or urography and those who had hematuria secondary to any other pathology like urinary tract stones, renal carcinoma etc. were excluded from the study. Urinary tract ultrasonography and urography were performed by different duty consultant radiologists. Ultrasonography was performed with Toshiba just vision and Toshiba Capasi machines available in the radiology department. All patients had renal tract and abdominal ultrasound examination performed with full bladder. The bladder was examined with transverse and vertical probes. Scanning was performed both pre and post micturition. Urography was carried out following empiric bowel preparation and included plain KUB X-ray and $5 \mathrm{~min}, 15 \mathrm{~min}$, $30 \mathrm{~min}$ and post void films. It was done without tomography.

All patients underwent cystoscopy and transurethral resection of bladder carcinoma. Confirmation of the bladder carcinoma was achieved by histopathogical examination of the submitted tumor in each case.

In all cases the reported findings of urinary tract ultrasonography and urography were correlated with those at cystoscopy.

\section{RESULTS}

The patient's age ranged from 18 years to 85 years (average 55 years). Male to female ratio was 4:1. Thirty seven patients had superficial and 63 patients had invasive bladder carcinoma. In 87 (87\%) patients urography accurately diagnosed the bladder carcinoma. In 13 patients urography failed to suggest the diagnosis due to various reasons (Table-1). In 86 patients there was no abnormality in the upper urinary tracts while in 14 patients various findings were reported. There was unilateral non-excretion of contrast in 3 patients with history of previous nephrectomy. In 2 patients there was good unilateral excretion but only
Table 1 - Failure of urography to detect bladder carcinoma $(n=13)$.

$\begin{array}{ll}\text { Clots in bladder } & 3 \\ \text { Poor excretion of contrast } & 1 \\ \text { Small tumors } & 6 \\ \text { Anterior wall tumor } & 1 \\ \text { Small capacity bladder } & 1 \\ \text { Deformed bladder } & 1\end{array}$

contralateral nephrogram. In 9 patients there was nonexcretion of contrast on one side. On the other hand urinary tract ultrasonography detected the bladder carcinoma in 96 (96\%) patients. In addition, ultrasonography accurately determined the size, location and multiplicity of bladder carcinomas. Ultrasonography failed to detect bladder carcinoma in 4 patients (Table-2). In 3 patients bladder carcinoma was missed on ultrasonography, all these tumors were small and less than $0.5 \mathrm{~cm}$. In one patient, the radiologist failed to detect a $3.5 \mathrm{~cm}$ bladder carcinoma and reported it as a vesical stone. In all those cases when urography failed to provide information about the upper urinary tract, ultrasonography accurately defined the pathology. In 3 patients there was unilateral absence of kidneys and in 11 patients there was hydronephrosis and hydroureter secondary to ureteric involvement by bladder carcinoma.

Smaller tumors detected on ultrasonography are shown in Figures- 1 and 2 while smallest tumors detected on urography are shown in Figures- 3 and 4.

The data show that the proportion of the correctly detected bladder carcinoma by ultrasonography is higher (0.96) than this proportion by urography (0.87). For testing of this hypothesis we applied the test of equality of 2 proportions. The value of $\mathrm{Z}$ is 2.28 , which is statistically significant ( $\mathrm{p}$ $<0.01)$.

Table 2 - Failure of ultrasonography to detect bladder carcinoma $(n=4)$.

Small tumors

Tumor falsely reported as vesical stone

3

1 


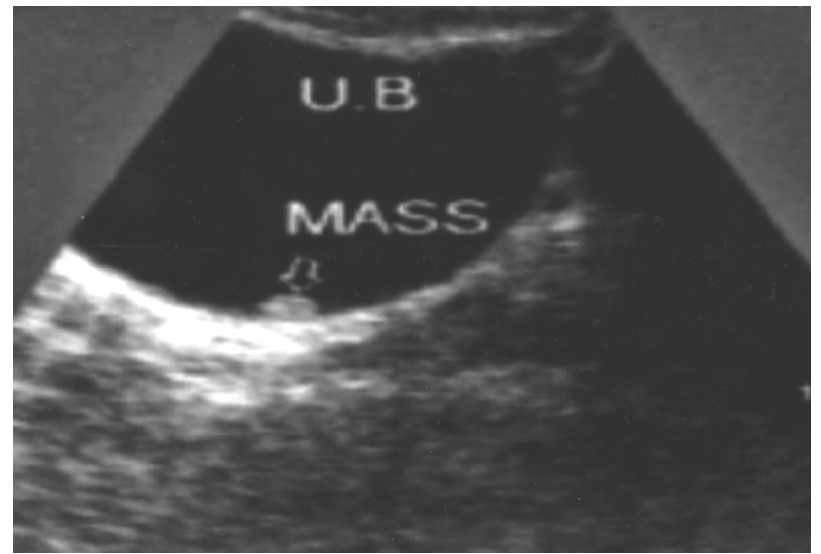

Figure 1 - A small tumor $0.9 \times 0.6 \mathrm{~cm}$ in left posterolateral wall of urinary bladder.

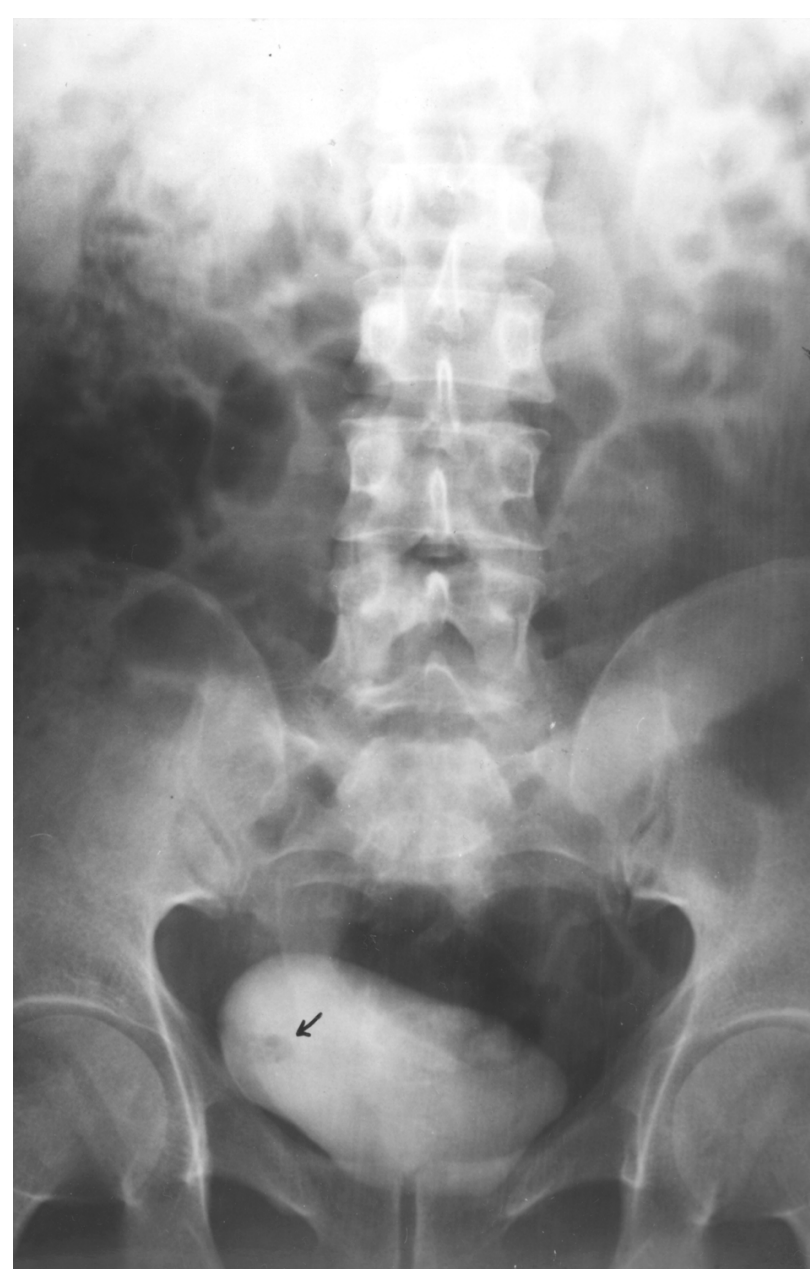

Figure 3 - An intravenous urogram showing a small papillary tumor as filling defect in the right lateral wall of urinary bladder.

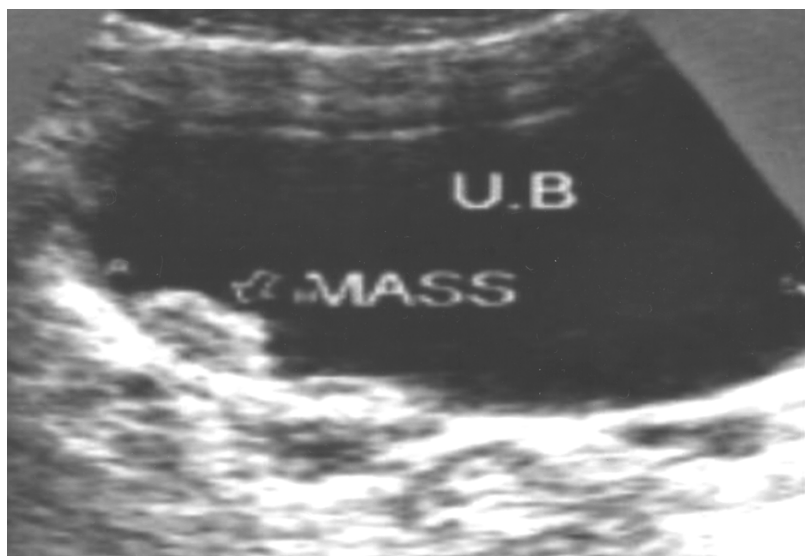

Figure 2 - A tumor $1.8 \times 1.4 \mathrm{~cm}$ in left posterolateral wall of urinary bladder.

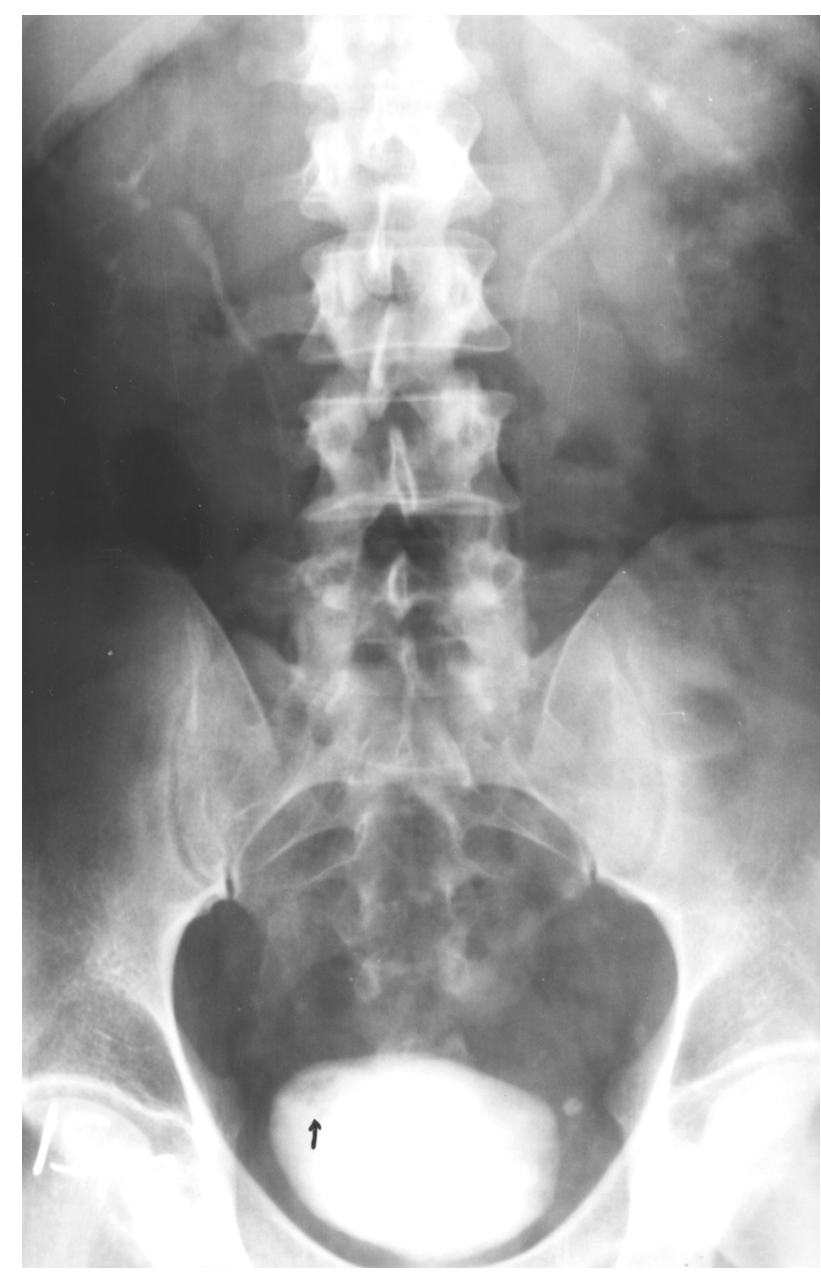

Figure 4-An intravenous urogram showing a small solid tumor as filling defect in the right lateral wall of urinary bladder. 


\section{DISCUSSION}

The standard initial investigations most useful for patients presenting painless hematuria secondary to bladder carcinoma include urine microscopy, urine cytology, intravenous urography and ultrasonography.

The traditional initial radiological investigation has been intravenous urography. Useful information about the primary bladder carcinoma can be obtained from urography (7). Scrupulous technique is required to eliminate artifacts caused by under-filling or external compression (8). Large tumors appear as filling defects in the bladder on cystogram phase of urogram. Small tumors may not be seen on urography as they are lost in the contrast medium in full bladder and in postvoid films it may be difficult to recognize them as the urothelium of collapsed bladder adopts a corrugated configuration. Tumors within a bladder diverticulum may not be seen on urography (9). Urography has its own risks. It exposes the patient to a small risk of ionizing radiation, equivalent to a $0.1 \%$ incidence of radiation induced carcinoma (10) and contrast induced renal failure has been reported in $0.8 \%$ of patients without preexisting renal disease (11). In addition, severe adverse reactions occur in $0.22 \%$ of the ionic and $0.04 \%$ of the non-ionic contrast media examinations (12).

The reported detection rates of bladder carcinomas by urography range from $26 \%$ to $86 \%$ $(8,9)$. In addition authors vary in their confidence in detecting small carcinomas, quoting values of 0.5-1 $\mathrm{cm}$ as their lower limit of sensitivity $(5,7,9)$.

In the present study $87 \%$ bladder carcinomas were detected at urography and the size of the smallest tumors detected at urography was $1.5 \mathrm{~cm}$.

Urography as the standard investigation has been increasingly criticized over recent years, since the widespread introduction of ultrasonography. Technological improvements in ultrasound equipment have brought the diagnostic accuracy of this examination even superior to urography. Ultrasound depicts the bladder carcinoma as a soft tissue structure of low to intermediate echotexture projecting in to the filled urinary bladder lumen (13). The extent of invasion of bladder wall can be assessed with ultrasound. The echogenic line around the bladder is absent when a tumor has invaded the bladder wall (14). Transabdominal ultrasonography is a simple and quick investigation. It requires no special preparation and is not associated with any complication inherent to urography. It can safely be performed in elderly patients and those with renal failure.

Factors that affect the detection of bladder carcinoma include the operator's skill, obesity of patient and degree of bladder distension (15). Accurate detection also depends on the size and location of tumor. Tumors smaller than $0.5 \mathrm{~cm}$ can be difficult to detect (16) and tumors located in the bladder neck and dome can also be missed on sonography (17).

Regardless of the location and size, sonographic detection rates of bladder carcinoma range from $82 \%$ to $95 \%(16,17)$. In the present study the sonography detected $96 \%$ bladder carcinomas and the smallest carcinoma detected was $0.8 \mathrm{~cm}$ in size.

The major argument in favor of retaining the urography as the initial investigation is the exclusion of synchronous multifocal urothelial carcinoma in the upper urinary tract (18). Ultrasonography, however, is at a disadvantage compared with urography in that normal ureter is not identified and anatomical detail obtained of the renal pelvis is inferior.

Urothelial tumors of the upper renal tract are rare compared with bladder tumors and most ureteric tumors present upper tract dilatation, which would be identified by ultrasonography (19). In the present study no synchronous upper renal tract tumor was found. The other argument in favor of urography is that it can detect the ureteral dilatation caused by the muscle invasive bladder carcinoma (18). However, ureteric dilatation can be documented equally well by sonography (5). Because of the poor or nonexcretion of contrast, urography failed to depict the pathology of the affected upper renal tracts in 14 patients. Ultrasonography accurately defined the pathology in all such cases. In 3 patients no kidney was present because of previous nephrectomy and in others there was ureteric dilatation secondary to involvement of distal ureters by invasive bladder carcinomas.

In the present study ultrasonography was superior $(96 \%)$ to urography $(87 \%)$ in the detection 
of bladder carcinoma. By applying the test of equality of proportions the value of $\mathrm{Z}$ is 2.28 , which is statistically significant $(\mathrm{p}<0.01)$.

We recommend the utilization of ultrasonography as the initial radiological investigation for detection of bladder carcinomas in patients presenting with hematuria.
Ultrasonography is safe, easily available, cost effective and provides images of both upper and lower renal tract. We present a flow diagram (Figure-5) that will be helpful in investigating patients presenting with hematuria of suspected bladder carcinoma origin. It is hoped that by employing ultrasonography as primary imaging modality in patients with hematuria

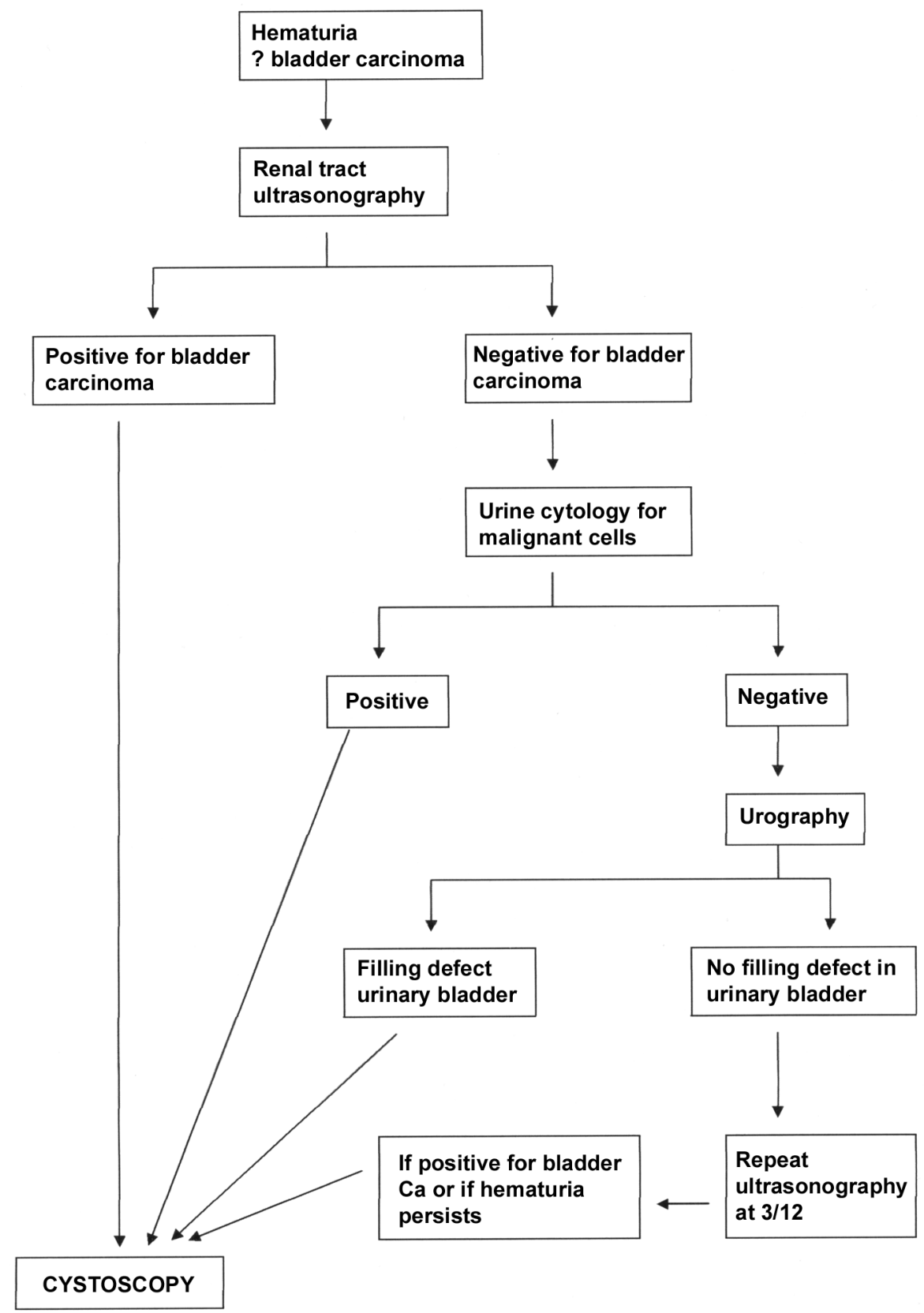

Figure 5 - Flow diagram for investigation of patients presenting with hematuria of suspected bladder carcinoma origin. 
more new cases of bladder carcinoma will be detected especially in developing countries where ultrasonography is easily available compared with urography. Patients diagnosed to be suffering from bladder carcinoma by ultrasonography should be scheduled directly and promptly for cystoscopy and bladder tumor resection.

\section{REFERENCES}

1. Black RJ, Bary F, Ferlay J, Parkin DM: Cancer incidence and mortality in European Union: cancer registry data and estimates of national incidence for 1990. Eur J Cancer. 1997; 33: 1075-9.

2. Parker SL, Tong T, Bolden S, Wingo PA: Cancer statistics.1997: CA Cancer J Clin. 1997; 47: 5-27.

3. Gardner BP, Doyle PT: Symptoms of bladder carcinoma. J R Coll Gen Pract.1987; 37: 367.

4. Ravi R, Rao RC, Ahlawat R, Berry M: Carcinoma bladder: Comparative evaluation of urinary cytology, excretory urography and ultrasonography. Indian $\mathbf{J}$ Cancer. 1990; 27: 55-61.

5. Gossel C, Knispel HH, Miller K, Klan R: Is routine excretory urography necessary at first diagnosis of bladder carcinoma? J Urol. 1997; 157: 480-1.

6. Herranz-Amo, Diez-Cordero JM, Verdu-Tartajo F, Bueno-Chomon G, Leal-Hernandez F, Bielsa-Carrillo A: Need for intravenous urography in patients with primary transitional carcinoma of the bladder? Eur Urol. 1999; 36: 221-4.

7. DeFelippo NP, Fortunato RP, Mellins HZ, Richie JP: Intravenous urography: important adjunct for diagnosis of bladder tumours. Br J Urol. 1984; 56: 502-5.

8. Amar A, Das S: Pre-cystoscopic diagnosis of bladder tumour by modified intravenous urography. $\mathrm{Br} \mathrm{J}$ Urol. 1984; 56: 381-4.

9. Corrigan NT, Crooks J, Shand J: Are dedicated bladder films necessary as part of intravenous urography for hematuria? BJU Int. 2000; 87: 806-10.

10. Mariani AJ, Mariani MC, Macchioni C, Stams UK, Hariharan A, Moriera C.: The significance of adult hematuria: 1000 hematuria evaluations including a riskbenefit and cost effectiveness analysis. J Urol. 1989: 141: 350-5.

11. Teruel JI, Marcen R, Onaindia JM, Serrano A, Quereda C, Ortuno J.: Renal function impairment caused by intravenous urography: A prospective study. Arch Int Med. 1981; 141: 1271-4.

12. Katayama H, Yamaguchi K, Kozuka T, Takashima T, Seez P, Matsuura K: Adverse reactions to ionic and non ionic contrast media, A report from the Japanese Committee on the safety of contrast media. Radiology. 1990; 175: 621-8.

13. Davidson AJ, Hartman DS, Choyke PL, Wagner BJ: Radiology of the kidney and genitourinary tract.. Philadelphia, WB Saunders, 3rd ed. 1999; pp. 485-515.

14. Sanders RL, Hundley SL: Hematuria. In: Sander RL (ed.), Clinical Sonography - Pracical Guide. Boston, LittleBrown. 1991; pp. 321-5.

15. Abu-Yousef MM, Narayan AS, Franken EA, Brown RC: Urinary bladder tumors studied by cystosonography. BJ Urol. 1989; 64: 409-11.

16. Malone PR, Weston-Underwood J, Aron PM, Wilkinson KW, Joseph AE, Riddle PR: The use of transabdominal ultrasound in the detection of early bladder tumours. Br J Urol. 1986; 58: 520-2.

17. Itzchak Y, Singer D, Fischelovitch Y: Ultrasonographic assessment of bladder tumors. I. Tumor detection. J Urol. 1981; 26: 31-3.

18. Leung HY, Grifiths DE, Neal DE: Bladder cancer. Postgrad Med J. 1996; 72: 719-24.

19. Spencer J, Lindsell D, Mastorakou I: Ultrasonography compared with intravenous urography in the investigation of adults with hematuria. BMJ. 1990: 301:1074-6.
Received: August 25, 2003

Accepted after revision: May 12, 2004

Correspondence address:

Dr. M Rafique

5, Altaf Town, Tariq Road

Multan. Pakistan

E-mail: rafiqanju@ hotmail.com 


\section{EDITORIAL COMMENT}

In this study, ultrasonography was effective in showing obstruction and involvement of the lower ureter by the bladder tumor. Ultrasonography does not adequately evaluate the mid or upper ureter or the upper collecting system and calices.

Regarding excretory urography; it is not, in most uroradiologist's opinion, an adequate examination for bladder carcinoma, and most will add the caveat of "cystoscopy is necessary to adequately evaluate the bladder for tumor" or something to that effect. The intravenous urography, done well (i.e. with nephrotomography), does provide excellent evaluation of the ureters and upper collecting system and that is its role; it thereby precludes the need for retrograde ureteropyelography either at the time of cystoscopy or later if the cystoscopy is negative.

But, in many countries, this approach of ultrasonography as the initial evaluation of patients with hematuria and suspected bladder cancers makes considerable sense as optimizing provision of health care, recognizing the limitations of ultrasonography and the need for a process so that patients with a "negative" ultrasonography do not escape adequate evaluation and followup.

In many countries where computed tomography (CT) scanning is readily available, the CT-urogram (multi-phase CT with noncontrast of abdomen and pelvis for calculi, nephrogram phase of the kidneys, and delayed imaging of the kidneys and ureters) is becoming the gold standard in evaluating patients suspected of having "surgical" hematuria not due to simple stone disease. However, this "high-tech" approach has disadvantages, i.e. higher radiation dose, high cost and impact on health care costs and, of course, availability.

Regarding the evaluation of bladder cancer, it is my impression that cystoscopy and biopsy is the gold standard. Newer magnetic resonance imaging techniques may ultimately be helpful, but confirmation of efficacy is still in progress.

The paper presents a nice flow diagram of patient management.

Dr. William H. Bush, Jr. Director, Genitourinary Radiology University of Washington Medical Center Seattle, Washington, USA 